\title{
"Segredos mais que secretos das princesas": reflexões sobre práticas de letramento literário a partir de uma abordagem intercultural $^{1}$
}

\author{
The most intimate secrets of the princesses: reflections about literary \\ literacy practices as of an intercultural approach
}

\section{Los secretos más ocultos de las princesas: reflexiones sobre prácticas de literacidad literaria a partir de un enfoque intercultural}

\author{
Santiago Bretanha Freitas ${ }^{1}$; Agnaldo Mesquita de Lima Junior²; Ida Maria Morales Marins ${ }^{3}$ \\ ${ }^{1}$ santiagobretanha@gmail.com, Universidade Federal do Pampa; ${ }^{2}$ agnaldo- \\ mesquita@ hotmail.com, Universidade Federal do Pampa; ${ }^{3 i d a m a r i a m a r i n s @ g m a i l . c o m, ~}$ \\ Universidade Federal do Pampa.
}

\begin{abstract}
Resumo
Vinculado ao projeto de extensão Experiências de leitura/escrita: formação de leitores/escritores, pertencente ao curso de Letras da Universidade Federal do Pampa (UNIPAMPA), câmpus Jaguarão, o presente trabalho objetiva relatar/refletir sobre práticas de letramento literário a partir de uma abordagem intercultural na rede básica de ensino. Tais práticas constituem o segundo módulo do projeto educacional (Di)versificando: diferença na escola, aplicado em uma instituição municipal de ensino de Jaguarão, no contexto do Programa Mais Educação (PME); oportunidade na qual os autores deste artigo concluíram seu estágio supervisionado de docência em Língua Portuguesa e Literatura. Com base nos pressupostos teórico-metodológicos de Cosson (2006), Di Nizo (2008) e Ruiz (2001), no que concerne, respectivamente, aos conceitos/metodologias da Sequência Expandida, das Técnicas de Criatividade e de revisão textual-interativa, organizou-se o projeto didático em torno de dois temas transversais: diversidade/diferença étnico-racial e relações gênero; em específico no módulo dois tratou-se, dentro do eixo "gênero", as questões das feminilidades e da mulher nos contos de fadas e nas "histórias de princesas", narrativas que foram analisadas junto aos alunos sob diferentes óticas temporais e contrapostas a outras materialidades e artefatos culturais. Como produto final desta intervenção, houve a publicação dos contos produzidos pelos alunos no A Folha do +, jornal confeccionado pela Oficina de Jornal do PME, que circula na escola. Por meio de uma reflexão crítica acerca do impacto do trabalho docente, evidenciou-se no discurso dos alunos embates entre a emancipação do feminino e o imaginário do "homem da casa", bem como novos olhares, modestos, sobre o papel sociocultural da mulher na contemporaneidade.
\end{abstract}

Palavras-Chave: formação de leitores, formação de escritores, letramento literário, didática intercultural, letramento intercultural.

\begin{abstract}
Bound to the extension project Experiências de leitura/escrita: formação de leitores/escritores, belonging to the course of Letras of the Universidade Federal do Pampa (UNIPAMPA), campus Jaguarão, the objective of this study is to report/reflect about literary literacy practices as of an intercultural critical approach at basic teaching network. Those practices make up the second module of the teaching plan (Di)versificando: diferença na escola, applied in a municipal school of Jaguarão, in the Programa Mais Educação (PME); opportunity in which the authors of this article have completed their supervised internship in Portuguese Language and Literature. Based on the theoretical and methodological assumptions of Cosson (2006), Di Nizo (2008) and Ruiz (2001), regarding, respectively, to the concepts/methodologies of the Sequência expandida, the "creativity techniques"
\end{abstract}

\footnotetext{
${ }^{1} \mathrm{O}$ presente trabalho é uma versão revista e ampliada do capítulo Princesas no limiar: práticas de letramento literário sob uma abordagem intercultural crítica, a ser publicado em um livro (no prelo), organizado pelo Programa de Escolas Interculturais de Fronteira (PEIF) da Universidade Federal do Pampa (UNIPAMPA) campis Bagé e Jaguarão.
} 
and the revision textual-interativa, the educational project was organized around two transversal themes: diversity/difference ethnic and racial and gender relationships; particularly on the module to which we referred, within the theme "gender", the issues of femininity and woman in fairy tales and stories of princesses have been problematized and analyzed with the students in differents temporal opticals and on opposition to other materialities and cultural artifacts. As a final product of this intervention, the tales of the students were published in the Folha do +, journal produced in the newspaper workshop of the PME, that circulates at school. Through a critical reflection about the impact of the teaching work, it was evidenced in the discourse of the students conflicts between the female emancipation and the imaginary of the "man of the house" as well as new perspectives, modest, over the social and cultural roles of the women in the contemporary society.

Keywords: readers formation, writers formation, literary literacy, intercultural didactic, intercultural literacy.

\section{Resumen}

Vinculado al proyecto de extensión Experiências de leitura/escrita: formação de leitores/escritores, perteneciente al curso de Letras de la Universidade Federal do Pampa (UNIPAMPA), campus Jaguarão, el presente trabajo tiene por objetivo relatar/reflexionar sobre prácticas de literacidad literaria a partir de un enfoque intercultural crítico en la rede básica de enseñanza. Esas prácticas constituyen el según módulo del proyecto educativo (Di)versificando: diferença na escola, aplicado en una institución municipal de enseñanza de Jaguarão, en el contexto del Programa Mais Educação (PME); oportunidad en la cual los autores de este artículo han concluido su pasantía supervisada de docencia en lengua portuguesa y literatura. Con base en los presupuestos teórico-metodológicos de Cosson (2006), Di Nizo (2008) e Ruiz (2001), en lo que dice respeto, respectivamente, a los conceptos/metodologías de la Sequência expadida, de las técnicas de creatividad y de la revisión textual-interativa, se ha organizado el proyecto didáctico alrededor de dos temas transversales: diversidad/diferencia étnico-racial y relaciones de género; en específico en el módulo dos se ha tratado, adentro del eje "género", las cuestiones de las femineidades y de la mujer en los cuentos de hadas y en las "historias de princesa", narrativas que fueron analizadas junto a los alumnos bajo distintas ópticas temporales y contrapunteadas a otras materialidades y artefactos culturales. Como producto final de esta intervención, hubo la publicación de los cuentos producidos por los alumnos en el A folha do +, periódico confeccionado por el Taller de Periódico del PME, que circula en la escuela. Por medio de una reflexión crítica acerca del impacto del trabajo docente, se ha evidenciado en el discurso de alumnos conflictos entre la emancipación del femenino y el imaginario del "hombre de la casa", así como el lanzamiento de nuevas miradas, modestas, sobre el rol sociocultural de la mujer en la contemporaneidad.

Palabras clave: formación de lectores, formación de escritores, literacidad literaria, didáctica intercultural, literacidad intercultural.

\section{A propósito de uma introdução}

Partindo do princípio pedagógico de uma prática docente dialógica, em que o professor (bolsista/estagiário) adote condição de mediador entre textos e leitores, o projeto de extensão Experiência de leitura/escrita: formação de leitores/escritores ${ }^{2}$ objetiva promover a experiência de leitura como aparato para o desenvolvimento da competência leitora e escrita em discentes da educação básica de diferentes escolas do município de Jaguarão. Desse modo, tal propósito é permeado pelo cerne que conduz esta intervenção: estimular o prazer pela

\footnotetext{
${ }^{2}$ O projeto de extensão Experiência de leitura/escrita: formação de leitores/escritores é vinculado ao curso de Licenciatura em Letras da Universidade Federal do Pampa (UNIPAMPA), câmpus Jaguarão. Vigente desde o ano de 2011, é coordenado pelas Professoras Dr. ${ }^{a}$ Ida Maria Morales Marins e Me. Cátia Dias Goulart, contando com a colaboração de bolsistas voluntários e estagiários. Para mais informações, acesse http://experienciasdeleitura.blogspot.com.br/.
} 
leitura/escrita, o senso crítico sobre as realidades, as culturas, os sujeitos e as identidades, e, assim, potencializar as diferentes leituras de mundo que os textos motivam.

O presente relato-reflexão, alocado nos parâmetros do projeto, constituiu-se por meio de práticas pedagógicas realizadas no contexto docente do estágio supervisionado em Língua Portuguesa e Literatura na Escola Municipal de Ensino Fundamental Mal. Castelo Branco, na oficina de Orientação Pedagógica do Programa Mais Educação (PME), com as Turmas A e B (segundo ciclo do Ensino Fundamental); as atividades compõem um módulo, de dois, do projeto de ensino (Di)versificando: diferença na escola. A faixa etária dos alunos girava em torno dos 12/14 anos de idade. As atividades do projeto perfizeram um total de 40 horas/aula, ao passo que o módulo 2 compreendeu cerca de um terço dessa carga-horária.

Os módulos foram: Um grito de negritude e Segredos mais que secretos das princesas. Estes versaram, respectivamente, sobre as diversidades/diferenças étnico-raciais e as relações de gênero, mesmo que, no transcorrer das práticas, tais temas transversais hajam sido problematizados em paralelo.

A partir disso, o objetivo do presente trabalho é o de relatar/refletir sobre as práticas de letramento literário, sob enfoque intercultural crítico, por nós realizadas no estágio curricular de docência em Literatura. Em específico, pretendemos explicitar a fundamentação teórica e metodológica que utilizamos, bem como o movimento de transposição didática que promovemos. Com isso, esperamos oferecer ao nosso público leitor acesso a um planejamento pedagógico que lhe motive ideias para o trabalho com o texto literário em classe,

Aqui, nos debruçamos sobre o $2^{\circ}$ módulo, Segredos mais que secretos das princesas. Fazendo uso de diversos artefatos culturais e obras literárias, buscou-se refletir, junto aos alunos, sobre a questão do gênero e as relações de poder que lhes são implicadas, tratando, em específico, dos imaginários de feminilidade(s) construídos pelos contos de fada e pela mídia. Procurando centrar as discussões na realidade dos alunos e em suas vivências, o pilar desta proposta se sustenta sobre três objetivos específicos: estimular a leitura de textos literários, fomentar um olhar crítico dos alunos sobre si mesmos e sobre o outro e a problematização da escrita literária a partir de uma posição consciente de autoria.

Para esse fim, nos baseamos: nos pressupostos da educação intercultural de Street (2007), Walsh (2010) e Candau (2012); nos postulados e objetivos dos Parâmetros Curriculares Nacionais (BRASIL, 1997) para a abordagem dos Temas Transversais nos currículos escolares; nas reflexões de Louro (1996, 2000, 2004, 2010) para a abordagem das relações de gênero em sala de aula; e, por fim, nos princípios teórico-metodológicos da sequência expandida, voltada ao letramento literário, proposta por Rildo Cosson (2011), da 
teoria de Escrita Criativa, alcunhada por Renata Di Nizo (2008), e do método textualinterativo para a revisão textual, apresentado por Eliana Ruiz (2010).

Com vistas à uma exposição concisa e didática, utilizamos a seguinte estrutura, acompanhada de introdução e considerações finais: Princípios teórico-metodológicos, em que, como explicitado no próprio título, trataremos os pressupostos teórico-metodológicos que ancoram nossa proposta, desde a abordagem intercultural da educação, até o tratamento do texto literário em classe e a problematização do gênero na escola; Transposição didática, seção na qual relatamos os procedimentos pedagógicos realizados na organização e aplicação do planejamento pedagógico; e, Por fim, em (In)conclusões e outras considerações, sugerimos um fechamento para nosso raciocínio, que se pauta pela impossibilidade de um "esgotamento" de sentidos.

\section{Princípios teórico-metodológicos}

\subsection{Didática e letramento intercultural: fundamentos}

Como princípio norteador, que subjaz à organização metodológica e à transposição didática, a serem posteriormente apresentadas, adotamos as reflexões sobre a educação intercultural e a didática crítica intercultural apresentadas por Walsh (2010) e Candau (2012) e as perspectivas interculturais sobre o letramento traçadas por Street (2007); ambas visões norteadas pelo vetor da interdisciplinaridade.

Segundo Candau (2012, p. 120), o interculturalismo se encontra em franco desenvolvimento no cenário da América Latina, tanto no que se refere aos movimentos sociais, quanto à produção acadêmico-científica e às políticas públicas. Porém, em específico, demonstra maior vasão no âmbito educacional.

De acordo com a autora, são 4 as etapas fundamentais em que se desenvolveu os impactos do interculturalismo na esfera da educação em contexto latino-americano: partindo da problematização da heterogeneidade linguística, da época colonial às primeiras décadas do século XX, e o advento dos movimentos sociais, mais fortemente nas últimas décadas do século XIX, até a estruturação da educação popular na América Latina, a partir da década de 60, e a "constitucionalização da diferença" por diversos países latino-americanos, entre as décadas de 80 e 90.

A educação indígena foi responsável por dar início à problematização intercultural, pois, por meio dela, reconheceu-se uma pluralidade étnica; nesse ínterim, estabelecido mais fortemente nos anos 10 e 20, que rompe com a lógica "aculturadora" do período colonial, as 
“diferentes línguas foram o passo inicial para a proposição de um diálogo entre diferentes culturas" (CANDAU, 2012, p. 122); em seguida, estabelecidos também como força motriz para o estabelecimento da lógica intercultural, se alocam os movimentos sociais, em especial os movimentos negros; a sua principal contribuição é a ruptura, brusca, que promove com relação ao imaginário de uma identidade nacional hegemônica europeizada e monocultural; trazendo, assim, a público a problematização das questões étnico-raciais. que passam a ser tratadas como políticas públicas, inclusive educacionais.

Em um terceiro momento, particularmente após a década de 60, começa a ser instaurada a popularização da educação na América Latina, também estabelecida em um universo plural, desdobrada de maneiras distintas em diferentes contextos. Conforme Candau (2012, p. 123), as experiências destas propostas educativas, pautadas pelo "abarcar a diferença" confluíram para estudos e reflexões diretamente relacionados à educação intercultural; movimento esse que recaiu em propostas de renovação de diversos sistemas escolares, principalmente no que concerne à afirmação de uma "intrínseca relação entre processos educativos e os contextos socioculturais em que estes se situam” (p. 124).

Por fim, em um quarto momento, que se constitui a partir das décadas de 80 e 90, numerosos países latino-americanos passam a reconhecer em suas Constituições "o caráter multiétnico, pluricultural e multilíngue de suas sociedades" (CANDAU, 2012, p. 124). Desta forma, a partir da admissão de tais caráteres, os parâmetros curriculares educativos desses países começam a adotar uma perspectiva intercultural, articulando nos currículos escolares os pressupostos das diferenças culturais enquanto Tema Transversal.

Assim, problematizado, a muito, o conceito de educação intercultural toma vulto na modernidade recente, assumindo, conforme Walsh (2010), enquanto palavra, uma natureza polissêmica. Ainda de acordo com a referida autora, são três as principais concepções que significam tal termo. São elas as concepções: relacional, funcional e crítica; as duas primeiras concepções dizem respeito, basicamente, ao contato e intercâmbio de culturas e à "assimilação de grupos socioculturais subalternizados à sociedade hegemônica, orientada a diminuir as áreas de tensão entre diversos grupos e movimentos sociais que focalizam questões socioidentitárias” (WALSH, 2010, p. 77-78).

A terceira concepção, a de educação intercultural crítica, concebida por Walsh (2010) e retomada por Candau (2012) é sobre a qual nos alicerçamos. Candau (2010, p. 127), dando enfoque a esta perspectiva, diz que:

Trata-se de questionar as diferenças e desigualdades construídas ao longo da história entre diferentes grupos socioculturais, étnico-raciais, de gênero, de orientação 
sexual, religiosos, entre outros. Parte-se da afirmação de que a interculturalidade aponta a construção de sociedades que assumam as diferenças como constitutivas da democracia e sejam capazes de construir relações novas, verdadeiramente igualitárias entre os diferentes grupos socioculturais, o que supõe empoderar aqueles que foram historicamente inferiorizados.

Assim, como afirmação política, a interculturalidade educacional relaciona-se estritamente à diferença, devendo prestar-se a papel de indutora à promoção da cidadania e da igualdade. Tendo por base essa afirmativa, Street (2007, p. 466), adotando a perspectiva do letramento sob a concepção funcional, assevera que "quaisquer que sejam as formas de leitura e escrita que aprendemos e usamos, elas são associadas a determinadas identidades e expectativas sociais acerca de modelos de comportamento e papéis a desempenhar".

Para que se alcance tal propósito, o estudioso elenca três abordagens indispensáveis: antes de tudo, é preciso aclarar e apurar os conceitos de letramento, rompendo com a dicotomia "letramento/iletramento"; em segundo lugar, devemos partir do contexto "onde as pessoas estão", "compreender os significados e usos culturais das práticas de letramento e traçar programas e campanhas com base nelas em vez de com base em nossas próprias suposições culturais acerca do letramento" (2007, p. 484); e, enfim, ligar a teoria desenvolvida pelos novos estudos de letramento com a experiência e os insights dos profissionais praticantes (professores, facilitadores, oficineiros, etc.) "que vêm trabalhando nesse campo há vários anos e que têm muito a nos ensinar acerca das necessidades e desejos das pessoas nessa área e dos problemas encontrados para atendê-los” (2007, p. 484).

Com vias à uma dialética entre as conjeturas funcionais e críticas da educação intercultural, cremos que a perspectiva crítica apontada por Candau (2010, p. 133) se mostra eficaz: supondo partir do "contexto onde se realizam as práticas educativas, os constrangimentos e as possibilidades que lhes são inerentes", ainda é fundamental uma postura (pró)ativa por parte dos docentes, que vise

desenvolver um diálogo crítico e propositivo orientado a fortalecer perspectivas educativas e sociais orientadas a radicalizar os processos democráticos e articular igualdade e diferença em todos os níveis e âmbitos, do macrossocial à sala de aula (Idem).

A partir desse intuito, o letramento literário sob a abordagem intercultural crítica, pautado em uma didática intercultural, assume para si um norte emancipador e empoderador, parâmetro para o estabelecimento de uma educação qualificada para todos(as).

\subsection{Temas transversais: gênero e educação em diálogo}


Com base no anteriormente exposto, compreendemos o letramento literário, em abordagem intercultural crítica, pautado no empenho em promover a cidadania, e, dessa forma, condizente com o objetivo primeiro dos Parâmetros Curriculares Nacionais (PCN) para o ensino fundamental; o de que os alunos sejam capazes de

compreender a cidadania como participação social e política, assim como exercício de direitos e deveres políticos, civis e sociais, adotando, no dia-a-dia, atitudes de solidariedade, cooperação e repúdio às injustiças, respeitando o outro e exigindo para si o mesmo respeito; (BRASIL, 1997, p. 6).

Ainda, de acordo com os PCN, para que se alcance tal intento, é indispensável "uma prática educacional voltada para a compreensão da realidade social e dos direitos e responsabilidades em relação à vida pessoal, coletiva e ambiental” (BRASIL, 1997, p. 15). É nessa perspectiva que os Temas Transversais, seus objetivos e conteúdos, são incorporados ao currículo escolar brasileiro e às diferentes áreas do conhecimento e trabalhos educativos.

Para tal, os PCN elegeram, com base na Constituição de 1988, os princípios segundo os quais deve se orientar a educação escolar; são eles a Dignidade da pessoa humana, a Igualdade de direitos, e a Participação e a Co-responsabilidade pela vida social. E, assim, um projeto pedagógico comprometido com estes pilares e com a promoção da cidadania poderá orientar-se a partir de três diretrizes (BRASIL, 1997, p. 24): a de "posicionar-se em relação às questões sociais e interpretar a tarefa educativa como uma intervenção na realidade no momento presente"; a de "não tratar os valores apenas como conceitos ideais"; e, principalmente, a de "incluir essa perspectiva no ensino dos conteúdos das diversas áreas de conhecimento escolar".

Por sua vez, estas diretrizes são permeadas pelos diferentes Temas Transversais elencados como parâmetro para os currículos escolares, desde a Ética, a Pluralidade cultural e o Meio ambiente, até a Saúde, a Orientação sexual e os Temas locais, perpassados pelos princípios da transversalidade ${ }^{3}$, e os diálogos mútuos entre esta e a interdisciplinaridade. ${ }^{4}$

É no campo da Orientação sexual em que inserimos as nossas práticas e reflexões. Conforme os PCN, são propostos três eixos para embasar a intervenções pedagógicas ao redor deste Tema: “Corpo Humano, Relações de Gênero e Prevenção às Doenças Sexualmente

\footnotetext{
3 "A interdisciplinaridade questiona a segmentação entre os diferentes campos de conhecimento produzida por uma abordagem que não leva em conta a inter-relação e a influência entre eles — questiona a visão compartimentada (disciplinar) da realidade sobre a qual a escola, tal como é conhecida, historicamente se constituiu. Refere-se, portanto, a uma relação entre disciplinas" (BRASIL, 1997, p. 31).

4 "A transversalidade diz respeito à possibilidade de se estabelecer, na prática educativa, uma relação entre aprender na realidade e da realidade de conhecimentos teoricamente sistematizados (aprender sobre a realidade) e as questões da vida real (aprender na realidade e da realidade)" (BRASIL, 1997, p. 31 ).
} 
Transmissíveis/AIDS". Ainda que possamos criticar essa organização, aparentemente calcada no discurso biológico sobre o corpo e o gênero, ademais de colocar-se no paradigma da cisgenericidade, nos enquadramos no eixo das Relações de Gênero.

No contexto acadêmico/educacional brasileiro, tais questões vêm sendo problematizadas sistematicamente, principalmente nos estudos que refletem sobre corpo, gênero, sexualidade e educação, tais como os geridos por Louro (2000, 2004, 2010), e os pesquisadores que se afiliam à sua abordagem pós-estruturalista e desconstrutivista sobre as práticas escolares e/para as diferenças.

Louro (1996), assevera em suas reflexões que o conceito de gênero é inconstante. Segundo a mesma, passa a ser empregado na década de 80, junto aos estudos sobre a mulher, em um espaço de resistência. Originado junto ao movimento feminista em seu caráter militante, o conceito vem sofrendo sucessivas transformações com os diálogos travados entre os estudos sobre a mulher, a História, a Literatura, a Antropologia e a Sociologia; debates que estimulam discussões teóricas e dão visibilidade ao sujeito feminino, até então silenciado, à margem.

Desta maneira, "gênero" surge com a proposta de contrapor a noção de "sexo". Enquanto o segundo se pautaria nas distinções biológicas entre mulher e homem ${ }^{5}$, o primeiro, desde a sua concepção, se refere à construção social do que se institui masculino ou feminino, definindo as determinações do que se se considera "masculinidade(s)" e "feminilidade(s)" enquanto construções que se realizam de acordo com os diferentes contextos sócio-históricos e culturais,

Partir desta concepção, a de gênero "enquanto constituído discursivamente e constituinte da identidade" (LOURO, 2010, p. 24), e, em uma visão mais recente, enquanto "ato intencional, um gesto performativo" (BUTLER, 2003), implica em reconhecer que o gênero determina os sujeitos centrais e os marginalizados no palco das relações de poder.

Assim sendo, tratar Gênero enquanto Tema Transversal na escola presume refletir sobre as identidades e como estas se configuram, para, por meio desta ação, pensar as práticas pedagógicas e os projetos educativos como promotores da igualdade, que rompam com os padrões hegemônicos e instrumentalizem os educandos para a cidadania através do respeito às diferenças; objetivo paralelo ao do letramento e da didática crítica interculturais.

\subsection{Letramento literário, escrita criativa e revisão textual: possibilidades}

\footnotetext{
${ }^{5}$ Desde o advento dos estudos culturais, em específico, dos estudos da mulher e das teorias queer, este conceito vem sendo desconstruído. Hoje, mantém significado distante do discurso biológico. Vide Preciado (2014).
} 
Levando em conta a fundamentação teórica até agora apresentada, as intervenções didáticas foram embasadas em três pressupostos metodológicos: a metodologia de Sequência expandida, voltada ao letramento literário, proposta por Cosson (2011); a teoria de Escrita Criativa, alcunhada por Di Nizo (2008); e o método textual-interativo para a revisão textual, apresentado por Ruiz (2010).

A metodologia da Sequência expandida para a obra literária, segundo Cosson (2011) se aloca como proposta humanizadora de letramento, que visa dar conta de instrumentalizar os professores para o trabalho com a leitura em sala de aula e, desse modo, por meio da formação oferecida aos educadores, proporcionar aos alunos uma aprendizagem holística da literatura. Com este fim, a metodologia se subdivide em 6 momentos: Motivação, Introdução, Leitura, Primeira Interpretação, Segunda Interpretação e Expansão; perspectiva metodológica que adotamos para o tratamento do texto literário em classe.

Em se tratando da teoria de Escrita Criativa, Di Nizo (2008) salienta a historicidade por detrás do Sujeito-autor na história do Brasil, em que a autoria é relegada à margem e à sombra do Sujeito-consumidor de literatura e de informações. Devido a isso, é evidente a grande dificuldade em estimular em sala de aula a posição de alunos-produtores. Ainda, segundo a autora, independentemente da posição social exercida pelo autor, a tarefa da escrita é árdua, porém, quando estimulada, passa a ser objeto de prazer. Desta forma, além de nos ancorarmos em algumas técnicas de escrita apresentadas pela autora, partimos do intuito de promover o "prazer pela escrita".

Em consonância com os postulados de Di Nizo coloca-se a metodologia de revisão textual apresentada por Ruiz (2001). Se, por um lado, a criatividade é fundamental para a escritura literária, por outro, o domínio dos diferentes registros da língua também são indispensáveis. Dado os alunos ainda estarem em processo de escolarização e familiarização com as práticas de linguagem da esfera escolar, é de suma relevância a intervenção do professor durante as produções em classe. A revisão textual-interativa cumpre tal papel; para além da indicação de possíveis necessidades de adequação linguística, esta metodologia se serve de feedbacks para aproximar aluno e professor no processo de ensino-aprendizagem, oportunidade em que sempre frisamos os aspectos positivos dos textos produzidos e propusemos a reescrita de pontos nebulosos.

Com vias a manter uma unidade lógica na construção da estrutura metodológica utilizada para a transposição didática, organizamos o módulo em dois momentos: primeiro, o de leitura das obras propostas, baseados na sequência expandida; e, segundo, o de produção 
escrita, fundamentada nas discussões realizadas em classe, facilitadas pelas técnicas de escrita criativa. Em seguida trabalhamos em duas etapas de revisão/reescritura; momento que culmina na nas produções finais, a serem socializadas sucessivamente nas edições do jornal em circulação na escola ${ }^{6}$.

\section{Transposição didática}

Com o objetivo de fazermos uma apresentação clara e uma exposição didática, mantivemos a estrutura metodológica, anteriormente apresentada, em formato de tópicos sobre os quais discorreremos, girando em torno eixos do letramento literário, sob um viés intercultural, e as atividades de escrita criativa; para relatar/refletir sobre as práticas, assim procedemos:

\subsection{A sequência expandida}

\subsubsection{Motivação/Introdução}

Neste primeiro momento da sequência expandida, apresentamos a temática da aula, em um processo de instrumentalizar e sensibilizar os alunos para/a "entrarem" na obra literária que proximamente será tratada. As discussões que levantamos em classe giraram em torno, primeiramente, sobre a situação das mulheres, e dos femininos, na sociedade atual e os papéis que desempenham nas famílias brasileiras.

Através dessa conversa, bastante genérica, projetamos o infográfico interativo "A nova mulher brasileira" (BERTELLI, 2015). O artefato cultural trouxe dados e estatísticas sobre a situação da mulher no cenário nacional, fornecendo informações variadas sobre a mulher em relação ao mercado de trabalho, ao âmbito acadêmico e ao que se refere ao casamento e ao número de filhos.

Como as informações trazidos se mostravam bastante normatizadas, questionamos os educandos acerca de se estas informações condiziam com a sua realidade familiar. Foi pedido aos jovens, caso não se sentissem inconfortáveis, que descrevessem a realidade das mulheres de suas famílias (as suas próprias, de suas mães, avós, irmãs e etc.). Nesse instante, passamos a contrapor a realidade narrada pelos alunos com o panorama apresentado pelo infográfico.

\footnotetext{
${ }^{6}$ Esta informação será contextualizada, suscintamente, na seção 3 - Transposição didática.
} 
Finalizamos as provocações com a questão "Vocês se enxergam, ou enxergam as mulheres que vocês conhecem, representadas na mídia e nas histórias que vocês leem?”.

Boa parte dos alunos responderam negativamente; em específico sobre as "histórias de princesa", levantadas pelos próprios alunos durante o diálogo, foi dito por uma das alunas que ela jamais seria uma princesa pois “princesas não são negras”. Respondemos, então, que, por meio de uma história divertida iríamos mostrar que ela sim, pode ser uma princesa.

Foi nesse momento que introduzimos a obra a ser lida, falando sobre a sua autora e dando spoilers sobre o seu título. Elegemos a obra Até as princesas soltam pum, de Iian Brenman (2008). Livro infanto-juvenil, distribuído em algumas escolas por meio do FNDE (Fundo Nacional de Desenvolvimento da Educação - BRASIL, MEC), trata da história de Laura que, incomodada pela questão de "se as princesas soltam pum", inquire seu pai sobre o assunto. Neste momento, o Pai da menina recorre ao "Livro secreto das princesas". No capítulo "Problemas gastrointestinais e flatulências das mais encantadoras princesas do mundo" encontra a resposta para as dúvidas de Laura.

\subsubsection{Primeira interpretação/Contextualização}

Retomando as discussões feitas na aula anterior, neste segundo momento da sequência expandida, começamos por inquirir os alunos sobre o que foi tratado sobre Ilan Brenman e o livro Até as princesas soltam pum. Como o assunto foi tratado "por alto", foram várias as inferências que os alunos fizeram devido à escassez de informações; entre si, os alunos puseram que decidimos por ler a história de uma "princesa peidona".

Feito o levantamento dos conhecimentos prévios necessários à leitura da obra, passamos à uma leitura coletiva da obra, em que cada um leria um parágrafo do texto, tanto nós, quanto os alunos. Utilizamos, para tal, a metodologia da leitura protocolada, que se baseia no sequenciamento do texto tanto para que se faça previsões e inferências sobre os sentidos estritos da obra, como possibilite a construção do sentido global do texto por meio de estratégias de leitura. Com esta finalidade, fizemos uso da obra disposta em slides, sequenciada, e interposta por questionamentos orais previstos (semiestruturados) em planejamento prévio; a leitura apenas foi interrompida para que se fizessem as intervenções necessárias

Desta forma, por meio dos protocolos de leitura, tratamos a primeira interpretação e a contextualização em paralelo; na primeira buscamos a compreensão global da obra, e, na segunda procuramos aprofundar a leitura realizada levando em conta os diferentes contextos 
que o texto literário traz consigo. Nesse sentido, o papel do professor é fundamental na mediação entre o domínio discursivo da obra e a realidade do aluno.

Sobre o contexto, o abordamos sob duas perspectivas: primeira, a histórica, quando intentamos recuperar alguns traços históricos que transpassam a obra, como as representações de mulher explícitas nos contos de fadas, intertexto da obra Até as princesas soltam pum; e, segunda, a presentificadora: em um movimento reverso, pretendíamos problematizar junto aos alunos a correspondência entre a leitura da obra e o presente, e, além, entre os sentidos construídos pelo/no texto e os seus próprios contextos.

\subsubsection{Segunda interpretação/Expansão}

Se anteriormente buscamos uma leitura global e uma leitura contextualizada do Até as princesas soltam pum, nesta aula o objetivo contorna uma leitura tematizada, isto é, segundo Cosson (2009, p. 92), o momento em que "interpretação da obra pode ser aprofundada com base em um dos aspectos do texto que seja mais pertinente para os propósitos do professor".

Fazendo uso da mesma estratégia empregada na aula anterior, demos início ao período letivo retomando com os alunos as principais discussões. Novamente levantados os conhecimentos prévios dos jovens, seguiremos as discussões sobre o livro, porém, desta vez, tratando, estritamente, dos segredos das princesas, presentes no capítulo "Problemas gastrointestinais e flatulências das mais encantadoras princesas do mundo", utilizados pelo pai da personagem Laura para evidenciar que sim, as princesas soltam pum.

Os segredos trazidos à tona falavam dos "deslizes flatulentos" de algumas princesas dos contos de fadas, tais como Branca de Neve, Cinderela e a Pequena Sereia. A intensão que permeia a seleção destes contos como intertexto é o de "humanizar as princesas". Visando o estabelecimento de relações intertextuais pelos alunos, começamos a relembrar os clássicos infantis; neste instante, a maior referência foi a produção fílmica da Disney. Por meio do estabelecimento destes diálogos, buscamos problematizar como o feminino e a mulher são representadas nas narrativas: sob a égide de suas famílias, fragilizadas, dependentes da figura masculina do príncipe...

Em boa parte das discussões os estudantes se mostraram desconfortáveis: primeiramente pois estavam sendo desconstruídos, pois, de certa maneira, os contos de fadas lhes constitui e, em segundo lugar, pois se deram conta que estes contos, e respectivas 
releituras em filme, não dão conta da diversidade em que se inserem. A figura do negro, do gordo, da mulher que trabalha foram as mais comentadas como ausentes.

Demonstrada esta inconformidade, os alunos foram postos como agentes ativos na construção das narrativas: foi-lhes solicitado que fizessem um desenho "livre" em que deveriam representar um possível segredo de alguma personagem dos contos de fadas, em que, tal qual na obra de Brenman, fossem pensadas representações daquilo que considerassem como "princesa possível”, e, acima de tudo, "mulher possível”.

Conforme esperado por nós, as representações em desenho giraram ao redor do "humor": as figuras femininas foram tratadas pelos alunos com barba e bigodes, unhas dos pés grandes, ou ainda cheirando mal... Outras tinham pelos "no sovaco", mal hálito ou piolhos. Os discentes, autonomamente, trocavam os desenhos entre si, salientando, quando o faziam, as características "ridículas" de suas princesas. Após essa socialização espontânea, os desenhos foram recolhidos, sem que fosse estimulada discussão sobre eles.

\subsection{Escrita criativa, revisão textual e produção final}

\subsubsection{Proposta de escrita criativa/revisão}

Dando prosseguimento às atividades, e, de certa forma, encerrada a primeira sequência de atividades que compõem o módulo Segredos mais que secretos das princesas, demos início às atividades de escrita criativa. $\mathrm{O}$ primeiro passo que investimos foi o de retomar, uma vez mais, as problemáticas levantadas durante a sequência expandida, isto é, concatenar as intepretações que surgiram ao redor da obra Até as princesas soltam pum, bem como as análises da obra a partir do prisma restrito das representações das feminilidades.

Partindo desta retomada das ideias principais, até então, tratadas, passamos a contrapor o que foi levantado com os desenhos feitos pelos alunos. Para tal, fizemos alguns questionamentos: "vocês creem que os seus desenhos contradizem ou reafirmam as representações sobre a mulher dos contos de fadas?"; "Caso os desenhos produzidos dissessem respeito a vocês, representassem vocês, como se sentiriam tendo seus segredos expostos?"

Nesse momento, boa parte dos alunos se deu conta que haviam representado as princesas da mesma forma "negativa" que as "histórias de princesa", segundo seu próprio julgamento. Ainda, outros, a partir de uma autorreflexão, se deram conta que haviam "ridicularizado" as princesas que desenharam com características que também possuíam, desde o cabelo crespo, até o pé grande. 
Com as problematizações ainda em seu auge, propusemos aos alunos que, agora, por meio do "seu próprio poder de autoria", escrevessem novas histórias para as princesas que desenharam; independentemente da representação que haviam feito. Com a personagem principal delimitada, suas características físicas e psicológicas, a tarefa de escrita dos contos foi facilitada. Os alunos ficaram livres para adequar as características dos contos à necessidade que tivessem, sem um número de linhas ou estrutura rígida estabelecidas; deveriam apenas seguir, de forma livre, a lógica estrutural da narrativa que já haviam aprendido no ensino regular.

Os jovens se demonstraram instigados em produzir os contos, mesmo que, alguns destes tenham se mostrado reticentes em produzir; de acordo com eles próprios, "estavam com preguiça". Seguimos insistindo fizessem a produção, nos prontificando a auxiliá-los na idealização de suas histórias.

No fim das contas, os contos escritos foram lindamente elaborados, apesar da recorrência de inadequações gramaticais e ortográficas. Com vias a sanar esta dificuldade, em um segundo momento, levamos os textos revisados para os alunos, seguidos de um feedback dos textos, em que foram salientados os aspectos positivos das narrativas, bem como foram explicitados, quando necessário, pontos nebulosos que mereciam atenção.

Por fim, em um terceiro momento, atendemos, individualmente, cada aluno, para que o texto fosse revisado novamente, agora pelos olhos do seu autor; revisão mediada por nós. Finalizada as revisões, foi pedido aos alunos que reescrevessem os seus contos levando em conta os apontamentos que fizemos, a revisão que eles próprios haviam traçado e os ajustes que julgassem necessários, dada a maturação do processo criativo.

\subsubsection{Produção final}

Feita a finalização dos textos, os alunos foram consultados sobre a sua concordância, ou não, de que seus textos fossem publicados em uma seção literária do jornal A folha do +, editorado e escrito na Oficina de Jornal, também do PME da Escola Castelo Branco. Os alunos entraram em acordo e decidiram que gostariam que suas obras fossem publicadas.

Os contos estão sendo periodicamente divulgados.

Com vias a tornar visível os produtos finais do módulo, abaixo, transcrevemos três narrativas:

\section{A princesa Isabel}


Era uma vez uma princesa chamada Isabel e um príncipe chamado Daniel, eles eram casados. Ela estava grávida.

Passaram-se meses e meses e a princesa Isabel teve dois filhos gêmeos. Um se chamava Júlio e o outro era Dani. Passaram-se dias.

A princesa se separou do marido. Ela passou por muitas dificuldades para cuidar dos bebês, até que um dia eles cresceram.

A princesa Isabel sempre quis muito viajar, mas seus filhos tinham apenas dois anos. Ela foi viajar, e seus filhos também. Eles foram para Nova York. Demorou 2 dias para eles chegarem, e, quando chegaram, fazia muito frio; mesmo assim eles ficaram; e ficaram felizes para sempre.

Aluna 1, 13 anos, turma B

\section{A princesa Mindinga}

Era uma vez uma princesa que era muito chique, vivia com muito glamour, até que um dia guerreiros inimigos atacaram o seu reino. Foi um massacre! Sangue e guardas mortos para todos os lados. A princesa conseguiu fugir por uma passagem secreta.

Como não tinha onde morar, ficou na rua. Para não ser assassinada, se vestiu como uma mendiga. Assim, ela virou Mindinga.

Aluno 1, 12 anos, turma A

\section{A Pequena Sereia com piolho}

A Pequena Sereia sempre ia para a escola.

Um dia a sua mãe disse:

- Filha, você vai ter que raspar o cabelo!

A menina estava cheia de piolhos!

Ela seguiu vivendo a sua vida normal; com o tempo o cabelo cresceu.

Aluna 2, 11 anos, turma B

\section{4. (In)conclusões e outras considerações}

As perspectivas interculturais, didática e para o letramento, e a temática transversal das Relações de gênero transpassam a eleição dos princípios metodológicos acima postos, principalmente no que concerne ao tratamento do texto literário. Todas as etapas da Sequência expandida presumem adequação ao contexto sociocultural dos alunos, bem como estimulam a 
pulverização das interpretações para além da materialidade do texto, buscando o estabelecimento de relações intertextuais e interculturais, presumidamente mobilizadas por um leitor "maduro", ou "em vias de"; essas relações se põem tanto na relação leitor-textoautor e seus contextos sócio-históricos e culturais, como no "colocar-se" no lugar de outrem, isto é, propor-se, mesmo que virtualmente, a um movimento de alteridade.

Através do discurso dos alunos, tanto em seus textos, quanto em suas falas, ficaram evidentes olhares, modestos, sobre o papel sociocultural da mulher na contemporaneidade. Embora em dados momentos, as produções e as leituras demonstraram uma postura "conservadora" sobre algumas questões, tais como as relacionadas à liberdade sexual da mulher, contudo, em vários outros, contemplaram a (re-)humanização do feminino e o empoderamento das "princesas", que passam a assumir papel autônomo frente a égide familiar e a tutela do marido, como explicitado no conto A princesa Isabel. Outras representações ainda foram tecidas, tais como a determinação de uma "identidade princesa" independente da aparência física: mendiga, ou com a cabeça raspada, mesmo fora dos "padrões de beleza", seguem sendo princesas, tal como retratado em A princesa mindinga e $A$ pequena sereia com piolho.

Dessa maneira, o trabalho com o texto literário em uma abordagem intercultural assume um papel humanizador, pois trata o leitor enquanto sujeito ativo, e não indivíduo passivo; promove o respeito às diferenças e às diversidades, desde que estimula os sujeitos a reconhecerem e a valorizarem as histórias, as culturas e as identidades que compõe o seu contexto, bem como a as histórias, as culturas e as identidades que compõe o contexto do "outro"; o letramento literário, por meio de uma reafirmação intercultural, desta forma, torna fluída as relações entre o $e u$, o nós e os outros, ratificando a constituição dialógica dos sujeitos.

\section{Referências}

BERTELLI, C. Infográfico: a nova mulher brasileira. Disponível em: <http://delas.ig.com.br/comportamento/2012-12-17/infografico-a-nova-mulherbrasileira.html>. Acesso em: 02 out. 2015.

BRASIL. Secretaria da Educação Fundamental. Parâmetros Curriculares Nacionais: apresentação dos temas transversais, ética. Brasília: MEC/ SEF, 1997

BRENMAN, I. Até as princesas soltam pum. São Paulo: Brinque-Book, 2008.

BUTLER, J. Problemas de gênero: feminismo e subversão da identidade. Rio de Janeiro: Civilização Brasileira, 2003. 
CANDAU, V. M. Escola, didática e interculturalidade: desafios atuais. In: (Org.).

Didática crítica intercultural: aproximações. Petrópolis, Vozes, 2012. p. 107-138.

COSSON, R. Letramento literário: teoria e prática. São Paulo: Contexto, 2006.

DI NIZO, R. Escrita Criativa: o prazer da linguagem. São Paulo: Summus, 2008.

LOURO, G. L. Nas redes do conceito de gênero. In: LOPES, M. J. D.; MEYER, D. E.; WALDOW, V. R, (orgs.). Gênero e saúde. Porto Alegre: Artes Médicas, 1996.

O corpo educado: pedagogias da sexualidade. Belo Horizonte, Autêntica, 2000.

Um corpo estranho: ensaios sobre sexualidade e teoria queer. Belo Horizonte: Autêntica, 2004

Gênero, sexualidade e educação: uma perspectiva pós-estruturalista. Petrópolis: Vozes, 2010.

PRECIADO, P. B. Manifesto contrassexual: práticas subversivas de identidade sexual. São Paulo: n-1 edições, 2014.

RUIZ, E. M. S. D. Como se corrige redação na escola. Campinas: Mercado de Letras, 2001.

STREET, B. (1994). Perspectivas interculturais sobre o letramento. Revista de Filologia e Linguística Portuguesa da Universidade de São Paulo, n. 8, p. 465-488, 2007.

WALSH, C. Interculturalidad crítica y educación intercultural. In: VIAÑA, J. et al.

Construyendo Interculturalidad Crítica. La Paz, Instituto Internacional de Integración del Convenio Andrés Bello, 2010. p. 75-96. 